\title{
Investigation of "Unified Voltage Conditioner - UVC"
}

\author{
Mihail Antchev ${ }^{\dagger}$, Mariya Petkova $^{*}$, Vanjo Gourgoulitsov ${ }^{* *}$, and Hristo Antchev ${ }^{*}$ \\ $\dagger^{*}$ Dept. of Power Electronics, Technical University-Sofia, Sofia, Bulgaria \\ ${ }^{* *}$ Power Engineering and Electronics College, Technical University-Sofia, Sofia, Bulgaria
}

\begin{abstract}
In this paper, a power electronic converter which is composed of two converters - bidirectional AC/DC converter and Series Active Power Filter (SAPF), is discussed. Structural schemas and ways of operation of control systems of converters, which are used to eliminate non sinusoidal parts of the network source voltage, are presented. At the same time, the control used stabilizes the value of the voltage feeding the load. Taking in consideration the combined functions which the device executes, it may be called Unified Voltage Conditioner - UVC.
\end{abstract}

Key words: Active power filter, Power factor, Unified voltage conditioner

\section{INTRODUCTION}

Achievements of Power Electronics make possible the creation of different power electronic converters applicable in so-called Flexible AC Transmission Systems (FACTS). Classified survey of properties of such converters is made in [1]. The following converters are more well-known: Static VAR Compensator (SVC), Thyristor Controlled Series Compensator (TCSC), Static Synchronous Compensator (STATCOM), Unified Power Flow Controller (UPFC), Static Synchronous Series Controller (SSSC), Interline Power Flow Controller (IPFC), Convertible Series Compensator (CSC), etc. Several applications of these converters are presented in [2]-[5]. Comparative analysis between STATCOM and SVC, when a wind generator is used, is presented in [6]. Optimal control of Dynamic Voltage Restorer (DVR) is presented in [7]. Combination of the achievements of Power Electronics with those of informational technologies has brought the creation of Active Power Filters (APF) [8], [9]. Also, a Bidirectional Converter with a high power factor applicable in photovoltaic

Manuscript received Aug. 02, 2010; revised Jan. 20, 2012

Recommended for publication by Associate Editor Nam-Sup Choi.

${ }^{\dagger}$ Corresponding Author: antchev@tu-sofia.bg

Tel: +359-2-965-3321, Technical University-Sofia

*Dept. of Power Electronics, Technical University-Sofia, Bulgaria

${ }^{* *}$ Power Engineering and Electronics College, Technical

University-Sofia, Bulgaria generator is discussed in [10]. Voltage Conditioner Plate (VCP) is proposed to monitor the deviations in power quality of the network voltage [11]. APF operational principles, which are based on monitoring of transitory values of voltage and currents of supply network, might be used creating also others similar converters intended to improve the quality of electrical power which is meant for "sensible" consumers. Moreover, the common operation of shunt and series active power filters joined in so-called Unified Power Quality Conditioner (UPQC) is known [12]-[14].

The converter discussed in the paper has the following features: 1. It eliminates the distortions in the voltage of the source so that the consumer is fed with sinusoidal voltage with a very low harmonic coefficient. 2. It compensates changes in the source voltage value so that the consumer is fed with voltage with stabilized value. Or generally compensates disturbances in the value and harmonic spectrum of the source voltage and the consumer is fed with a sinusoidal voltage with a stabilized value. As it is seen, the converter performs functions both of the active power filter and $\mathrm{AC}$ voltage stabilizator, because of that, it might be called "Unified Voltage Conditioner - UVC". In the paper, a single-phase topology is examined. The results obtained might be used also in implementation of three-phase UVC. "Unified Voltage Conditioner -UVC" consists of two converters - Bidirectional AC/DC Converter and Series APF. Part II illustrates the block schema of the proposed UVC and includes its operational principle. The power schema of a single-phase topology is put in Part III. Also, in this part, 


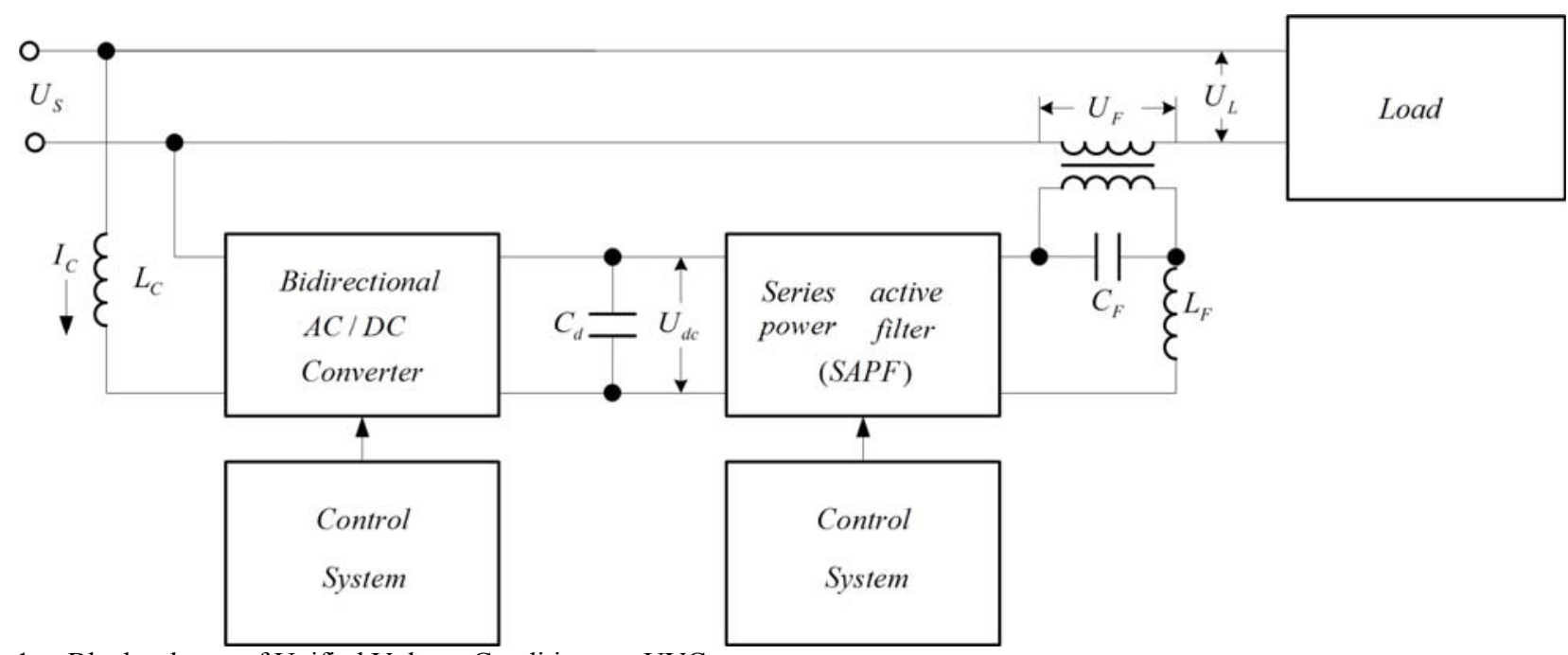

Fig.1. Block schema of Unified Voltage Conditioner - UVC.

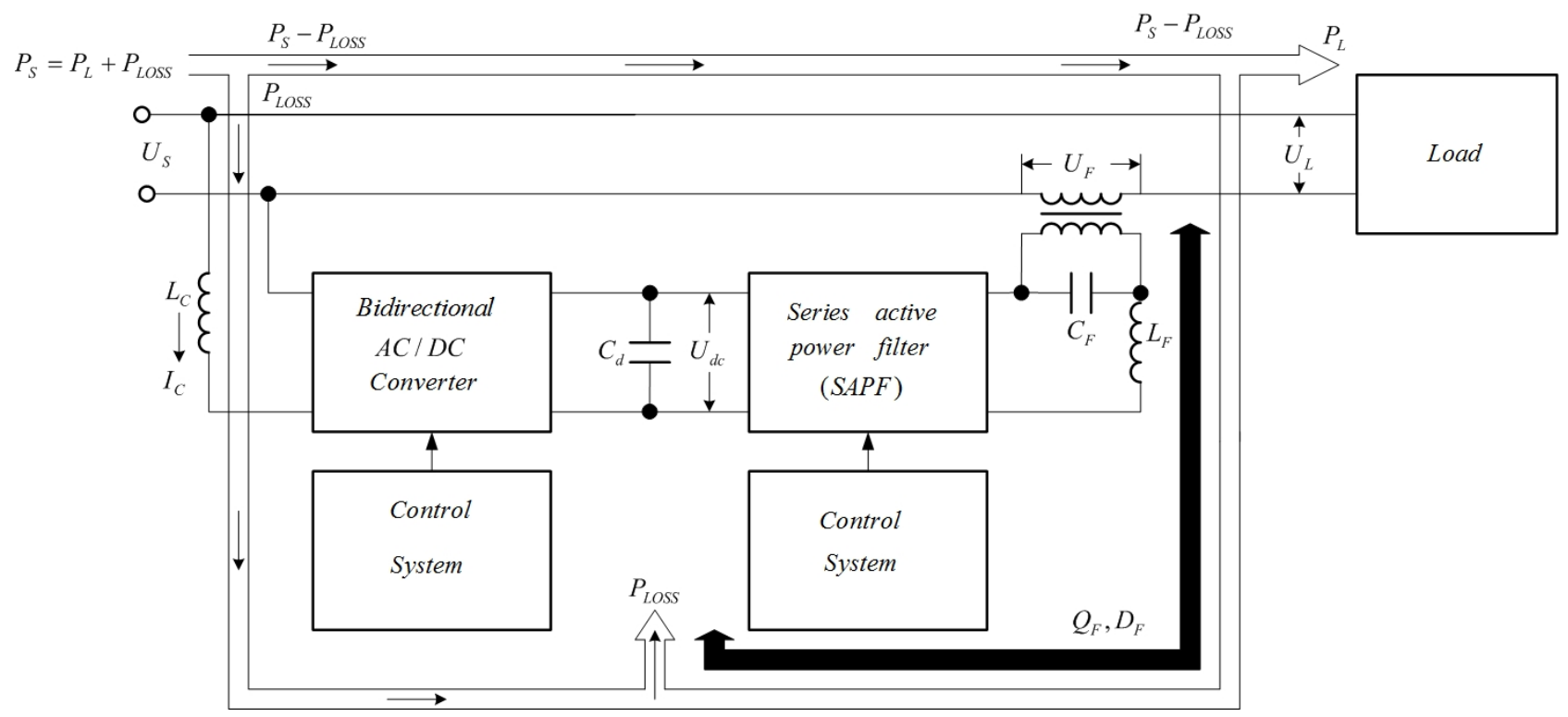

Fig. 2. The flow of active power when the first harmonic of the network voltage is equal to the stabilized value.

mathematical equations are derived and graphical results, connected with the design, are presented. Part IV includes structural schematics of control systems of the two converters and illustration of their operation. Experimental results are given in Part $\mathrm{V}$.

\section{PROPOSED CONVERTER AND ITS OPERATION}

Fig.1 displays the structural schema of Unified Voltage Conditioner - UVC. It consists of two converters Bidirectional AC/DC Converter - $\mathrm{BC}$ and Series Active Power Filter - SAPF. Each of the converters has its own control system.

The bidirectional converter $\mathrm{BC}$ maintains stable value of the intermediate DC voltage $U_{d c}$ across the capacitor $C_{d}$. At the same time, the converter input current $I_{C}$ is maintained always sinusoidal and it is in phase with or displaced at $180^{\circ}$ of the source voltage $U_{S}$. Therefore, the converter operates either in rectifier mode or in inverter mode but always with a power factor approximately equal to 1 . At voltage $U_{d c}$ tendency to decrease below the set value for stabilization, the value of the input current, which is in phase with the source voltage, increases. Furthermore, the consumed active power in rectifier mode increases and the value of $U_{d c}$ also increases. Alternatively, at voltage $U_{d c}$ tendency to increase above the set value for stabilization, the value of the input current, which at the beginning is in phase with the source voltage, decreases. Furthermore, the consumed active power in rectifier mode decreases and the value of $U_{d c}$ also has to decrease. Nevertheless, if the voltage value continues to increase that is due to a transfer of 


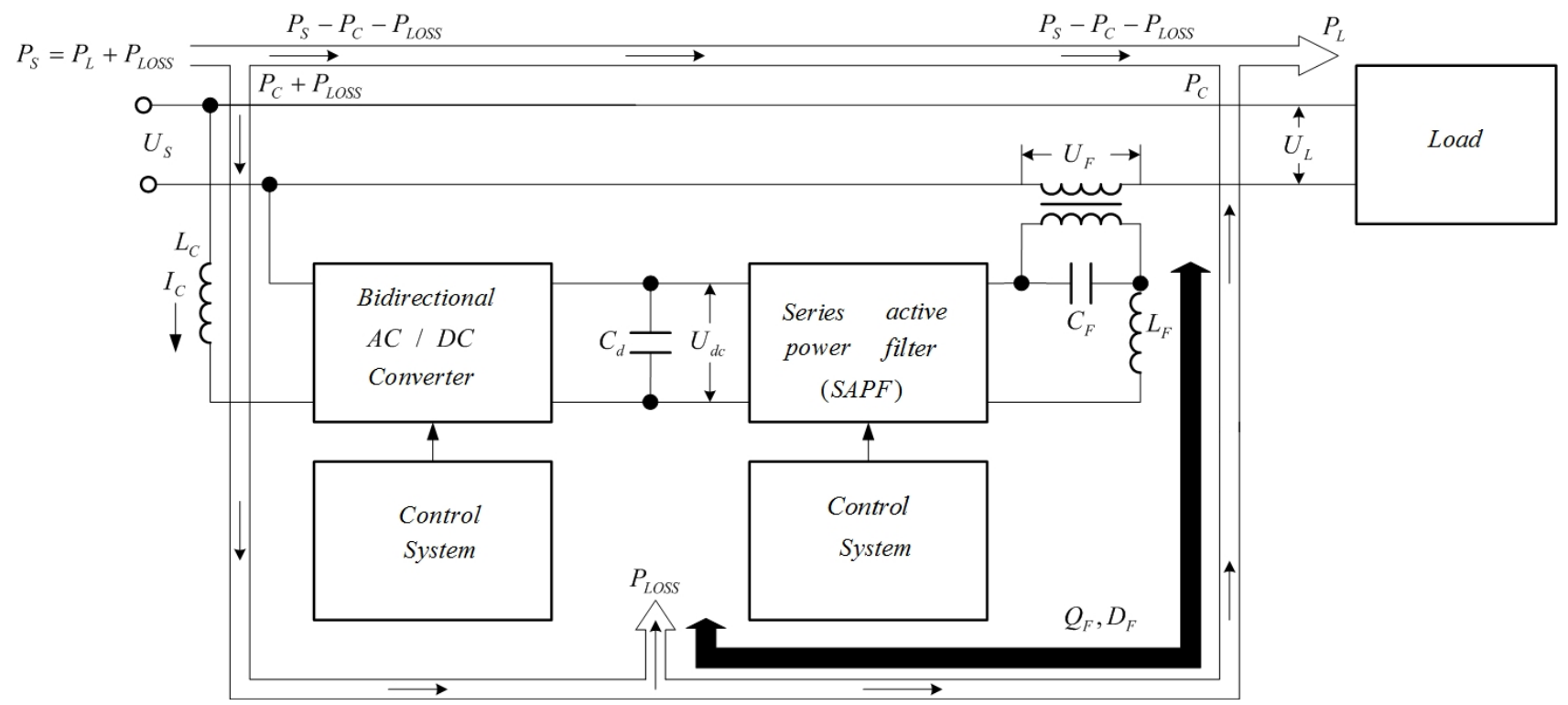

Fig. 3. The flow of active power when the first harmonic of the source voltage is lower than the stabilized value.

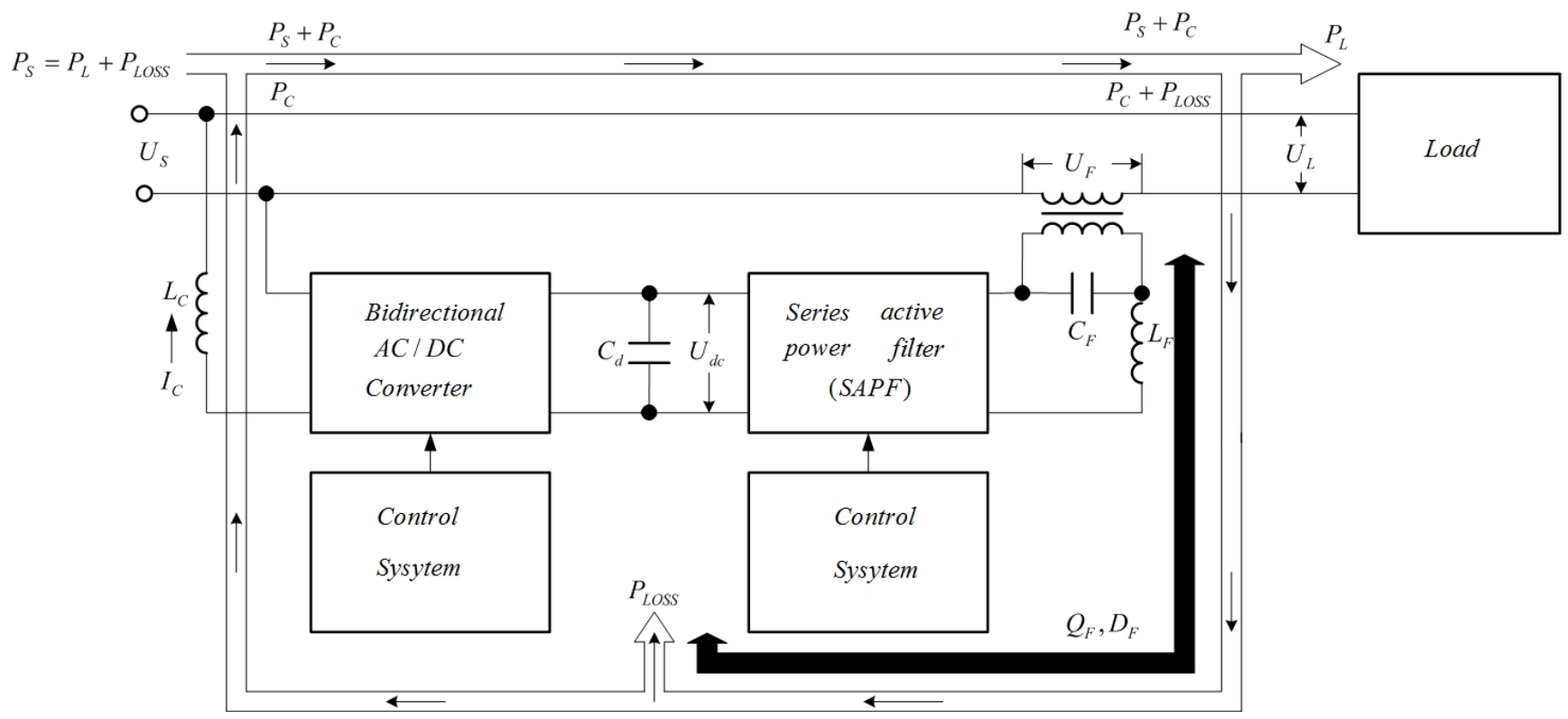

Fig. 4. The flow of active power when the first harmonic of the source voltage is higher than the stabilized value.

energy towards the $C_{d}$ from the series active power filter. Then the input current of bidirectional converter alters its phase and becomes displaced at $180^{\circ}$ of the source voltage $U_{S}$, and the current value gradually increases. Thus, the $\mathrm{BC}$ operates in inverter mode and the energy from the capacitor $C_{d}$ returns towards the source. This process causes a decrease in the value of the voltage $U_{d c}$ becoming near to the value of the stabilization. Therefore, the $\mathrm{BC}$ controls the flow of the active power towards or from UVC maintaining unchangable the value of the intermediate DC voltage $U_{d c}$ and also it operates with power factor equal to 1 .
Series active power filter - SAPF maintains the voltage across the load $U_{L}$ to be of sinusoidal waveform and to be equal to the preliminarily set value for stabilization. For this purpose the filter control system monitors a preliminarily set reference sine wave. The output voltage of the filter $U_{F}$ contains higher harmonics that compensate harmonics of the source network voltage. Besides, dependent on the difference between the value of the first harmonic of the network voltage $U_{S}$ and the value of stabilization, the output voltage $U_{F}$ contains also first harmonic in phase with or displaced at $180^{\circ}$ to the voltage $U_{S}$. 


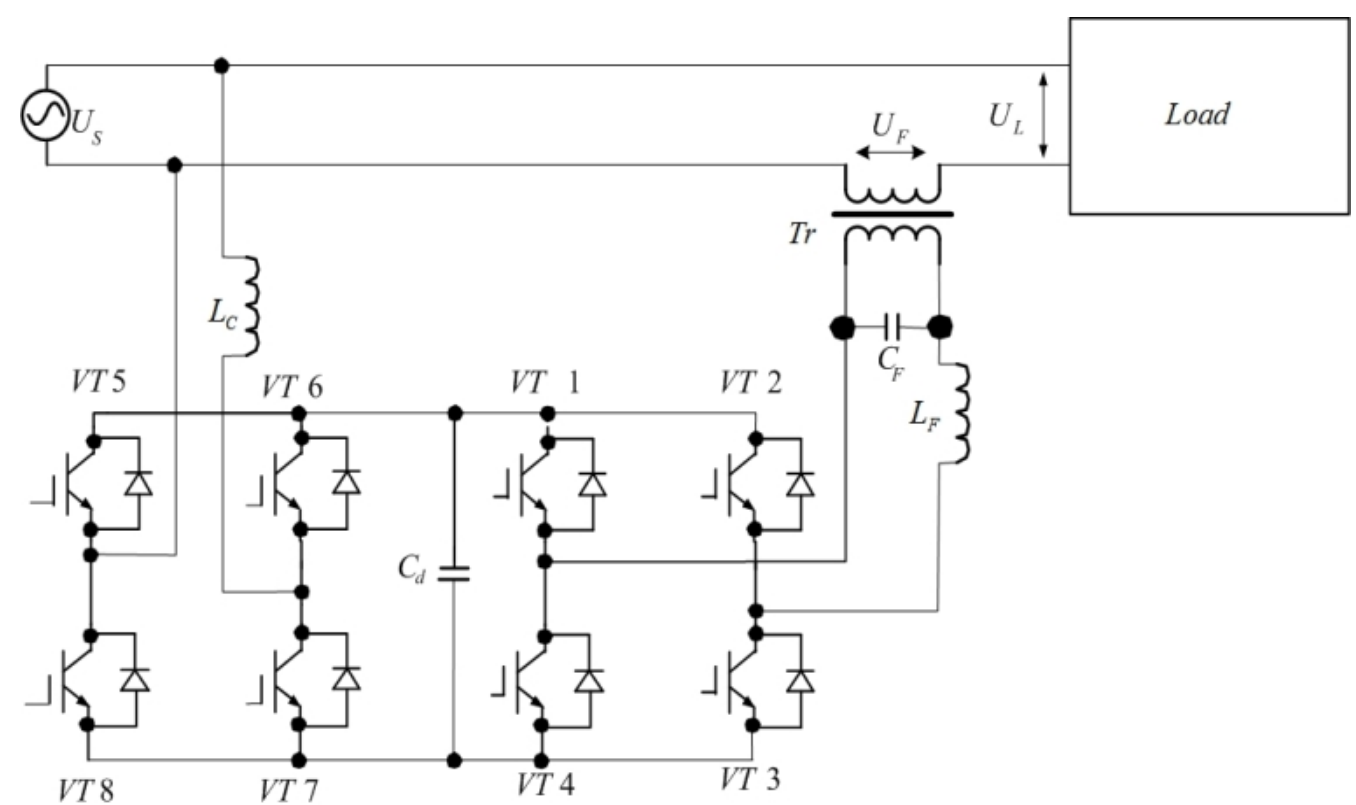

Fig. 5. Power schematic of Unified Voltage Conditioner - UVC.

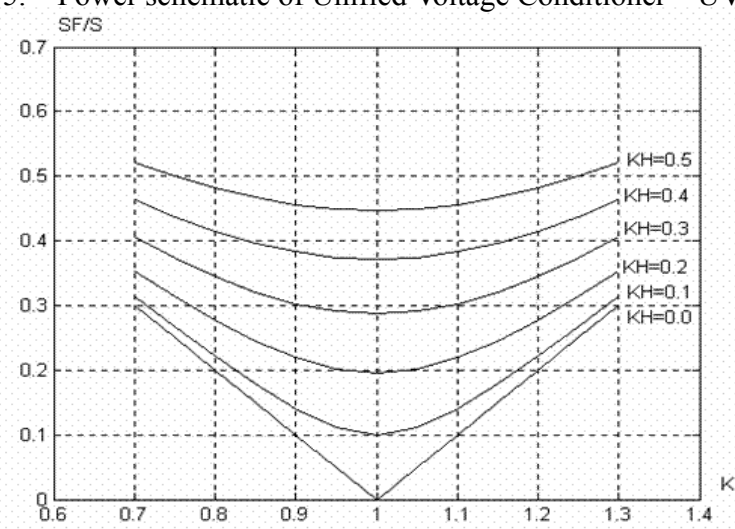

Fig. 6. Graphical relationships used to determine the power of SAPF corresponding to the equation (7).

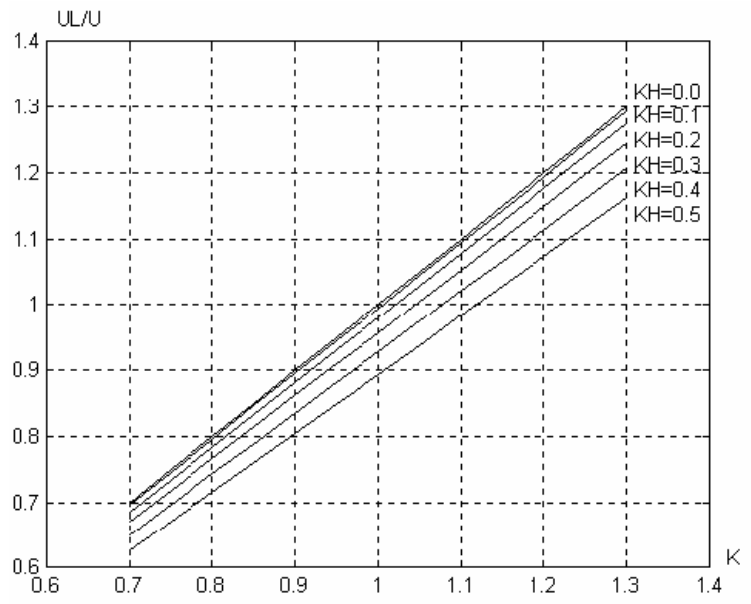

Fig. 7. Graphical relationships of the load voltage corresponding to the equation (8).

Fig.2 displays the motion of the flow of active power when

the first harmonic of the network voltage is equal to the stabilized value. The first harmonic of the voltage $U_{F}$ is equal to 0 . In the two converters there is loss power $P_{\text {LOSS }}$, which is ensured from the source network by the bidirectional converter BC operating in rectifier mode. This loss power exists in all operational modes and it is also displayed in all the following figures.

Fig. 3 displays the motion of the flow of active power when the first harmonic of the source voltage is lower than the stabilized value. In this case, the first harmonic of the voltage $U_{F}$ is in phase with the first harmonic of the voltage $U_{S}$, and the sum of the two harmonics gives the value of the voltage for stabilization. Using Unified Voltage Conditioner UVC, active power $P_{C}$ is ensured toward the consumer. The bidirectional converter $\mathrm{BC}$ operates in rectifier mode ensuring the flow of active power, shown in Fig.3, through the system of the two converters.

Fig.4 illustrates the motion of the flow of active power when the first harmonic of the source voltage is higher than the stabilized value. In this case, the first harmonic of the voltage $U_{F}$ is displaced at $180^{\circ}$ to the first harmonic of the voltage $U_{S}$, and the difference between the two harmonics gives the value of the stabilization voltage. Using Unified Voltage Conditioner - UVC active power $P_{C}$ from the consumer towards the source network is ensured. The bidirectional converter BC operates in inverter mode ensuring the flow of active power, shown in Fig.4, through the system of the two converters.

As it has been mentioned, in the three cases, besides the stabilization of the value of the first harmonic of the load voltage also filtering of the high harmonics of the source voltage by the series active power filter is ensured. Therefore the voltage $U_{F}$ contains these high harmonics. 


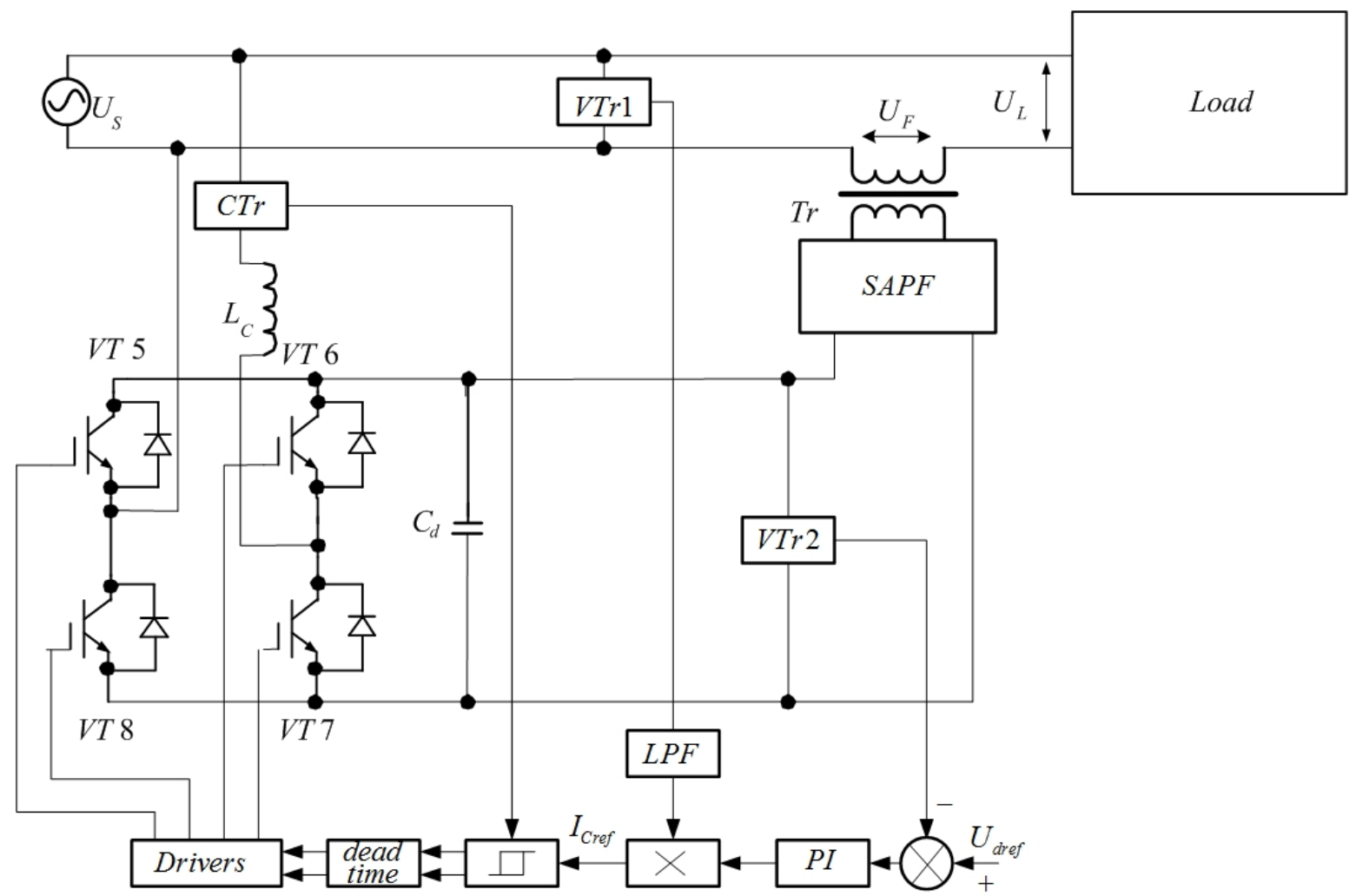

Fig .8. Block schema of the control system of Bidirectional AC/DC Converter.

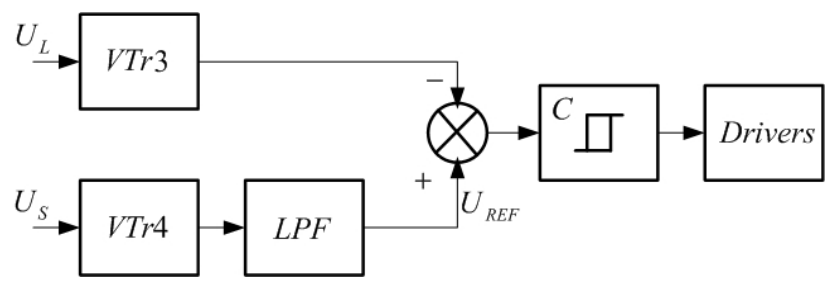

Fig. 9. Block schema of the control system of Series APF.

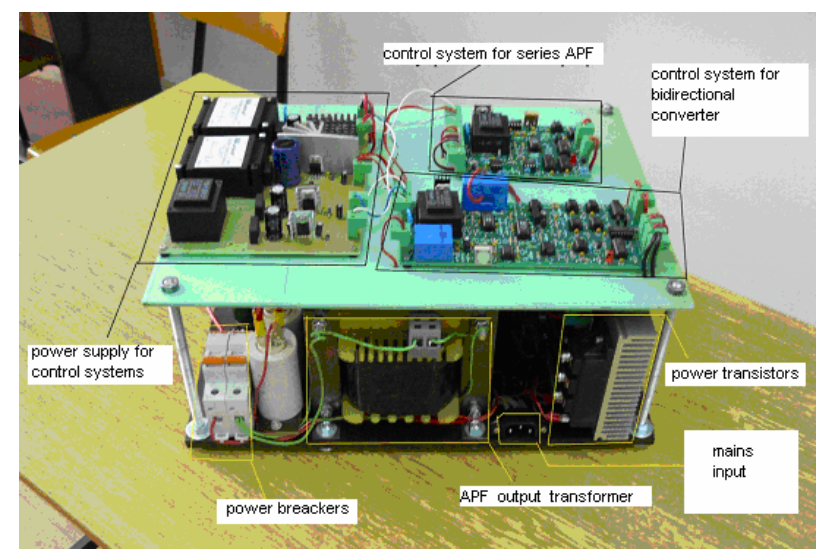

Fig. 10. Laboratory model of the single-phase UVC.

Their interaction with the load current determines the reactive power $Q_{F}$ and the distortion power of the active power filter

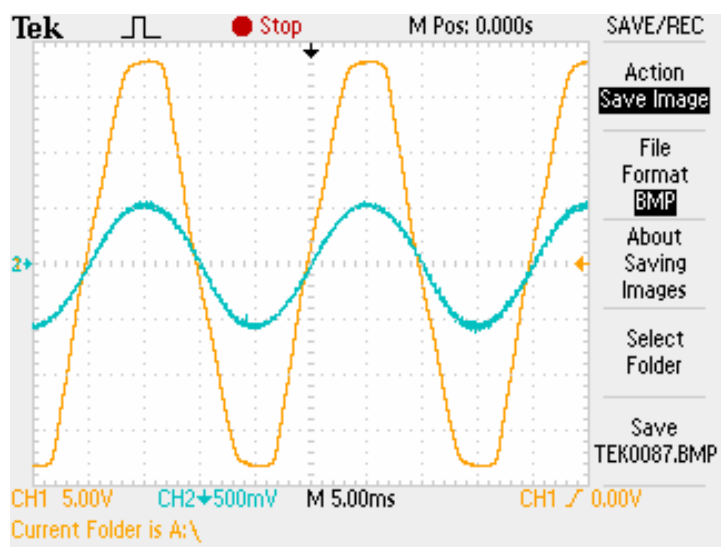

Fig. 11. Source network voltage $-\mathrm{CH} 1$ and source network current $-\mathrm{CH} 2$ in rectifier operational mode.

$D_{F}$. Fig.2, Fig.3 and Fig.4 illustrates the flow of these powers. As it is seen, the flow is ensured by the existence of the capacitor $C_{d}$ in the intermediate DC side.

\section{POWER CIRCUIT AND BASIC EQUATIONS}

Fig.5 displays the power schematic of Unified Voltage Conditioner - UVC.

Series Active Power Filter - SAPF consists of transistors $V T 1-V T 4$, as well as inductance and capacitor $L_{F}, C_{F}$. The bidirectional converter consists of transistors 


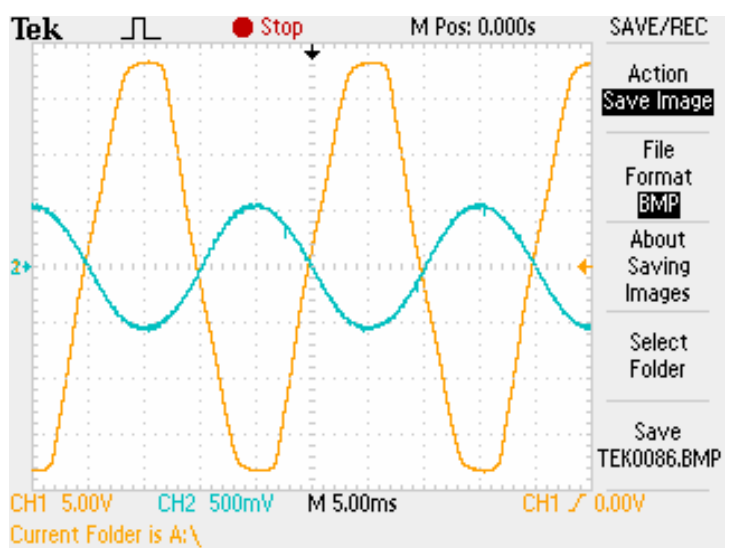

Fig. 12. Source network voltage $-\mathrm{CH} 1$ and source network current $-\mathrm{CH} 2$ in inverter operational mode.

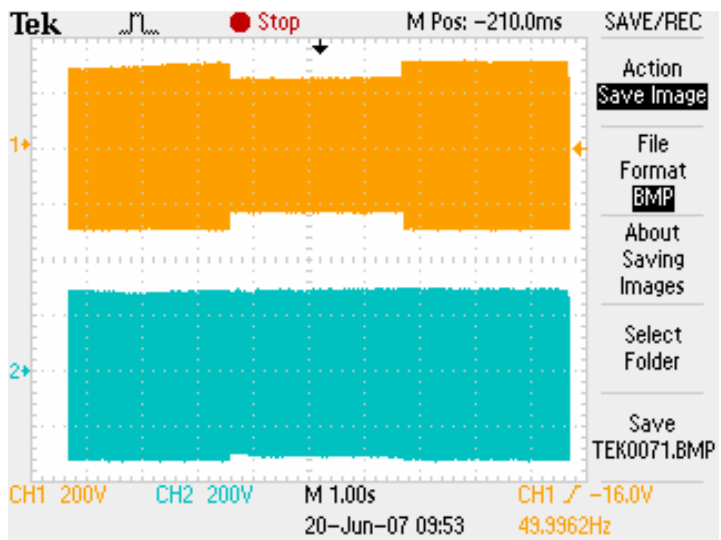

Fig.13. Step change of the voltage of the source network CH1 with $20 \%$ and the feeding voltage for the load - $\mathrm{CH} 2$.
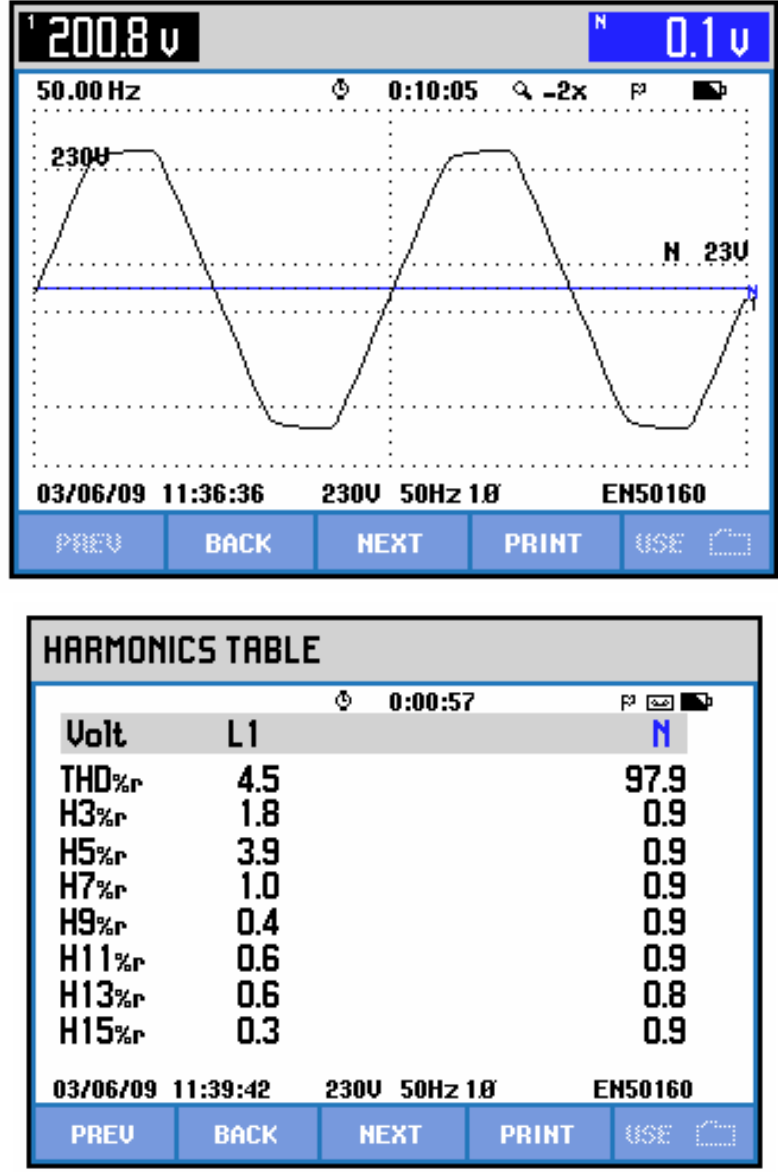

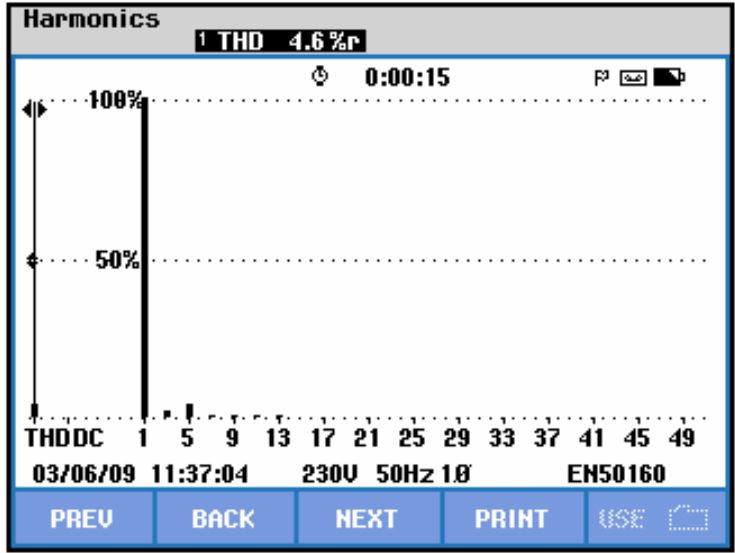

\begin{tabular}{|c|c|c|c|c|}
\hline \multicolumn{5}{|c|}{ HARMONICS TRBLE } \\
\hline Uolt & 0:00:2r & \multicolumn{2}{|c|}{ 0:00:27 } & $F^{2}$ \\
\hline $\begin{array}{l}\text { THD\%r } \\
\text { H17\%r } \\
\text { H19\%r } \\
\text { H21\%r } \\
\text { H23\%r } \\
\text { H25\%r } \\
\text { H27\%r } \\
\text { H29\%r }\end{array}$ & \multicolumn{3}{|c|}{$\begin{array}{l}4.5 \\
0.2 \\
0.1 \\
0.1 \\
0.1 \\
0.0 \\
0.1 \\
0.0\end{array}$} & $\begin{array}{r}98.4 \\
0.8 \\
0.9 \\
0.9 \\
0.8 \\
0.8 \\
0.9 \\
0.8\end{array}$ \\
\hline \multicolumn{2}{|c|}{ 03/06/09 11:53:40 } & \multicolumn{2}{|c|}{$230 \mathrm{U} 50 \mathrm{~Hz} 1.8$} & EH50160 \\
\hline PREU & BACK & HEXT & PRINT & \{s: $: \ldots$ \\
\hline
\end{tabular}

Fig. 14. Parameters of load voltage when Unified Voltage Conditioner - UVC does not operate.

$V T 5-V T 8$, as well as inductance $L_{C}$.

The calculation of the total power of SAPF depending on the load power and the load harmonic coefficient is of interest. The harmonic coefficient is defined as follows:

$$
K_{H}=\frac{\sqrt{\sum_{n=2}^{\infty} U_{n}^{2}}}{U_{1}}
$$

The series active power filter eliminates higher harmonics 

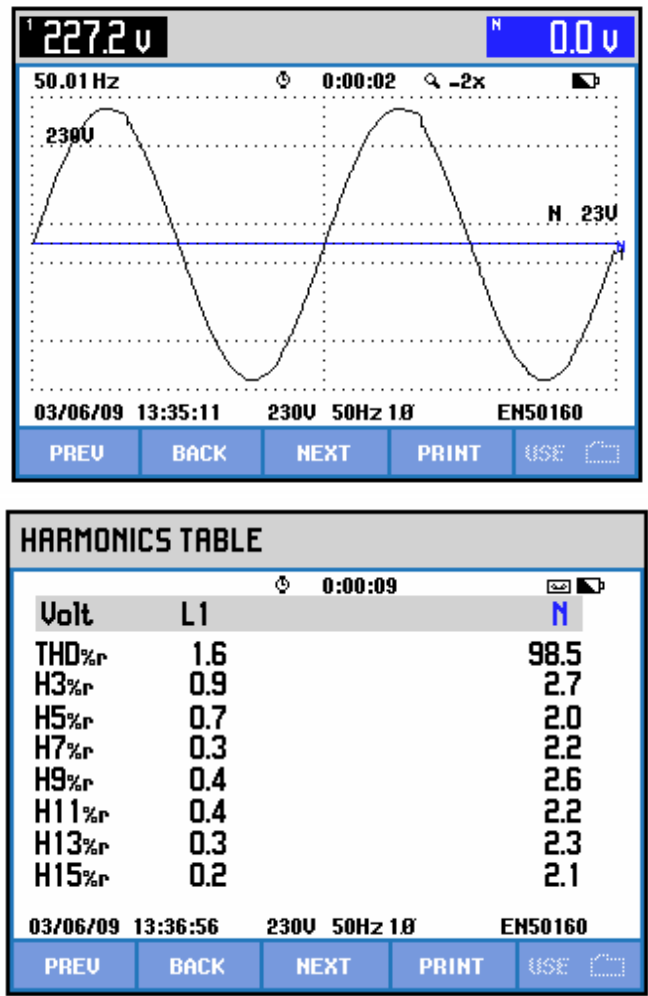

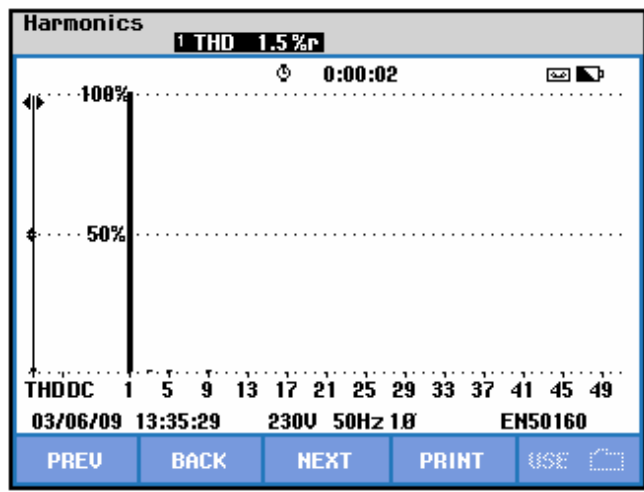

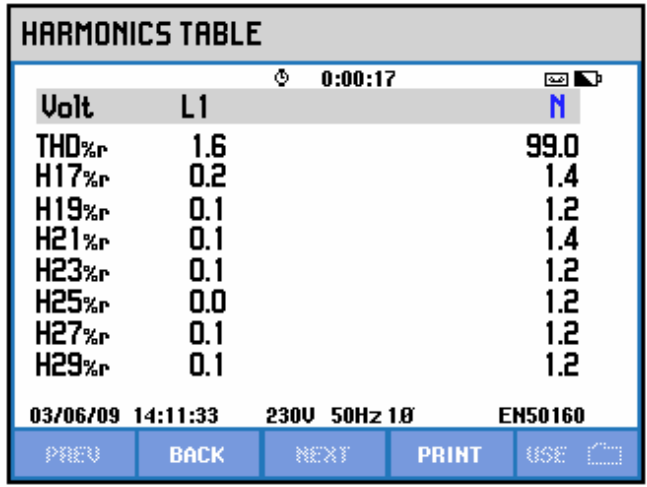

Fig.15. Parameters of load voltage when Unified Voltage Conditioner - UVC operates.

of the source voltage and the load is fed by sinusoidal voltage whose effective value is equal to a preliminarily set one. Therefore:

$$
U_{L}=U_{1 R}=\text { const }
$$

If the effective value of the output voltage of the SAPF, the set value of the first harmonic and the value of the nth harmonic are $U_{F}, U_{1 R}$ and $U_{n}$, respectively, then according to the operational principle, the following equation is valid:

$$
U_{F}^{2}=\left(U_{1 R}-U_{1}\right)^{2}+\sum_{n=2}^{\infty} U_{n}^{2}
$$

Let us mark the ratio of the effective values of the reference voltage (the set value) to the first harmonic of the source network voltage with $k$ :

$$
k=\frac{U_{1 R}}{U_{1}}
$$

then from (3) and (4) it is derived:

$$
U_{F}=U_{1} \cdot \sqrt{(k-1)^{2}+K_{H}^{2}}
$$

The ratio of the total power of SAPF $S_{F}$ to the total load power $S$ is:

$$
\frac{S_{F}^{2}}{S^{2}}=\frac{U_{1}^{2}\left[(k-1)^{2}+K_{H}^{2}\right] \cdot I^{2}}{\left[U_{1}^{2}+\sum_{n=2}^{\infty} U_{n}^{2}\right] \cdot I^{2}}=\frac{(k-1)^{2}+K_{H}^{2}}{1+K_{H}^{2}}
$$

Fig.6 and Fig.7 display graphical relationships corresponding to the following equations:

$$
\begin{gathered}
\frac{S_{F}}{S}=\sqrt{\frac{(k-1)^{2}+K_{H}^{2}}{1+K_{H}^{2}}} \\
\frac{U_{L}}{U}=\frac{U_{1 R}}{U}=k \cdot \sqrt{\frac{1}{1+K_{H}^{2}}}
\end{gathered}
$$

The obtained equations (7) and (8), as well as Fig.6 and Fig. 7 allow to determined the total power of a series active power filter, as well as the change of the effective value of the load voltage compared to this of the source network voltage, when the harmonic coefficient of $U_{S}$ is known.

\section{CONTROL SYSTEMS}

The following methods are applicable to control APF-s pulse-width modulation, sliding mode control, hysteresis-control, Fuzzy logic control, genetic algoritms[15], [16].

Similar methods are used in control of UPQC-s [17]. In this paper a PI-controller and hysteresis-control are applied. Fig. 8 displays a block schema for implementation of the control system of Bidirectional AC/DC Converter. The hysteresis-current control method similar to those applied at Shunt APF [18], [19] is used. The value of the intermediate DC voltage across the capacitor is continuously monitored 


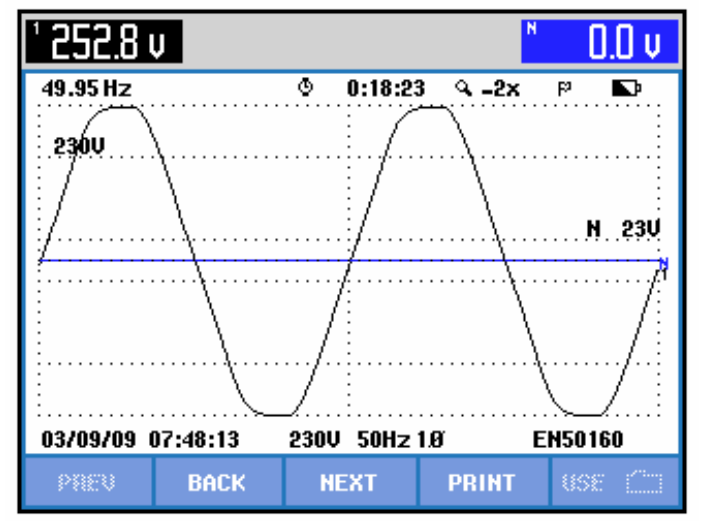

\begin{tabular}{|c|c|c|c|c|}
\hline \multicolumn{5}{|c|}{ HARMONICS TRBLE } \\
\hline Volt & L1 & 0:00:05 & & $\frac{1}{M}$ \\
\hline $\begin{array}{l}\text { THD\%r } \\
\text { H3\%r } \\
\text { H5\%r } \\
\text { H7\%r } \\
\text { H9\%r } \\
\text { H11\%r } \\
\text { H13\%r } \\
\text { H15\%r }\end{array}$ & $\begin{array}{l}3.2 \\
0.7 \\
3.0 \\
0.7 \\
0.2 \\
0.3 \\
0.1 \\
0.0\end{array}$ & & & $\begin{array}{r}98.4 \\
2.2 \\
2.4 \\
2.4 \\
2.1 \\
2.3 \\
2.4 \\
2.5\end{array}$ \\
\hline $03 / 09 / 09$ & $7: 50: 45$ & $230 \mathrm{U} 50 \mathrm{~Hz} 10$ & & EN50160 \\
\hline PREU & BACK & NEXT & PRINT & 经: \\
\hline
\end{tabular}

Fig. 16. Parameters of load voltage when UVC does not operate.

through Voltage Transducer VTr2. The result of its comparison to the reference value $U_{\text {dref }}$ is an input signal to the proportional-integral regulator PI. Through VTr1 the voltage of the source network is monitored, while using the low passed filter LPF the first harmonic is separated from the source network voltage. The zero crossing moments of this first harmonic coincide with those of the voltage $U_{S}$. After the multiplication of the separated first harmonic with the output signal from the PI-regulator, a reference sine wave $I_{\text {Cref }}$ for the source current is generated. Depending on the sign of the output signal of the PI regulator, this wave is in phase with or displaced at $180^{\circ}$ to the voltage $U_{S}$.

Using Current Transducer CTr1, the transitory values of the current $I_{C}$ consumed by the bidirectional converter are monitored. These values are compared to the values of the reference sine wave $I_{\text {Cref }}$. The result from the comparison using hysteresis comparator controls the drivers for the transistors of the bidirectional converter.

Fig.9 illustrates block schema to implement the control system of Series APF [20]. The transitory values of the voltage of the source network $U_{S}$ are monitored through Voltage Transducer 1 (VTr4). Thus, a continuous synchronization of the control system to the source network voltage is ensured. From the output voltage of VTr4 using

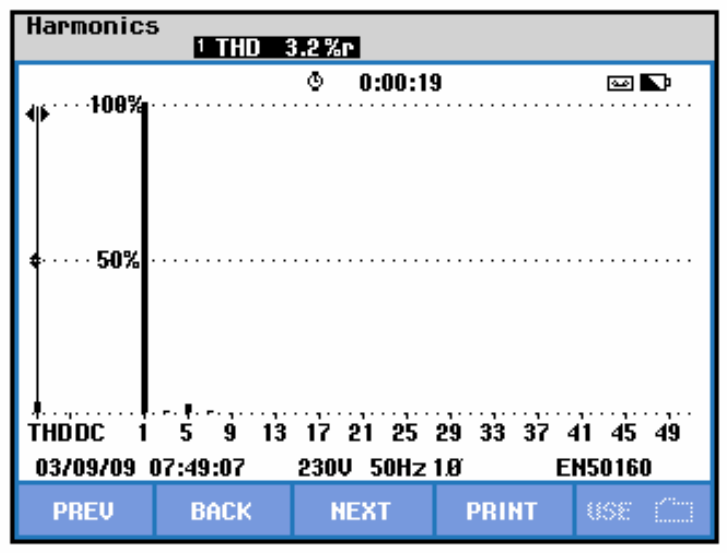

\begin{tabular}{|c|c|c|c|c|}
\hline \multicolumn{5}{|c|}{ HARMONICS TRBLE } \\
\hline & & \multicolumn{2}{|c|}{ (6) $0: 00: 37$} & \multirow{2}{*}{$\mathrm{F}^{2} \frac{\mathrm{⿴囗口}}{\mathrm{N}}$} \\
\hline Uolt & L1 & & & \\
\hline $\begin{array}{l}\text { THD\%r } \\
H 17 \% r \\
H 19 \% r \\
H 21 \% r \\
H 23 \% r \\
H 25 \% r \\
H 27 \% r \\
\text { H29\%r }\end{array}$ & $\begin{array}{l}3.3 \\
0.1 \\
0.0 \\
0.1 \\
0.0 \\
0.1 \\
0.1 \\
0.0\end{array}$ & & & $\begin{array}{r}98.1 \\
2.3 \\
\text { ㄹ.2 } \\
2.1 \\
2.1 \\
2.1 \\
\text { ‥1 } \\
\text { ‥2 }\end{array}$ \\
\hline \multicolumn{2}{|c|}{ 03/09/09 07:49:26 } & 230050 & & EH50160 \\
\hline PREU & BACK & HEXT & PRINT & 织: :...... \\
\hline
\end{tabular}

low pass filter (LPF), the first harmonic of the voltage is separated and its value is stabilized. Thus, reference sine wave for the load voltage $U_{L}$ is generated. The load voltage transitory values are monitored through VTr3 and they are compared to those of the reference sine wave. The result of the comparison through a hysteresis comparator (C) controls the drivers for the transistors of the bridge schematic of the Series APF.

\section{EXPERIMENTAL RESULTS}

Laboratory model of a single-phase version of UVC is studied -Fig.10. In it both converters are implemented using bridge schematic, transistors MII $75-12 \mathrm{~A} 3$ are used. The value of the intermediate DC voltage $U_{D C}$ is $360 \mathrm{~V}$, and the inductance $L_{C}-2.5 \mathrm{mH}$. The elements of Series APF have the following values: $L_{F}-2 \mathrm{mH}, C_{F}-5 \mu \mathrm{F}$. The power of the transformer $\operatorname{Tr}$ is $700 \mathrm{VA}$, which permits to the Series APF to compensate changes in the value of the input voltage (source network voltage) $\pm 15 \%$ around $230 \mathrm{~V}$ at a consumer power to $3 \mathrm{kVA}$. The output voltage (the input voltage for the consumer) is maintained to $230 \mathrm{~V} \pm 2 \%$ regardless the load type. Simultaneously, the Series APF permits the non sinusoidal parts of the input waveform to be compensated to $15 \%$. In the range to $3 \mathrm{kVA}$ Bidirectional 


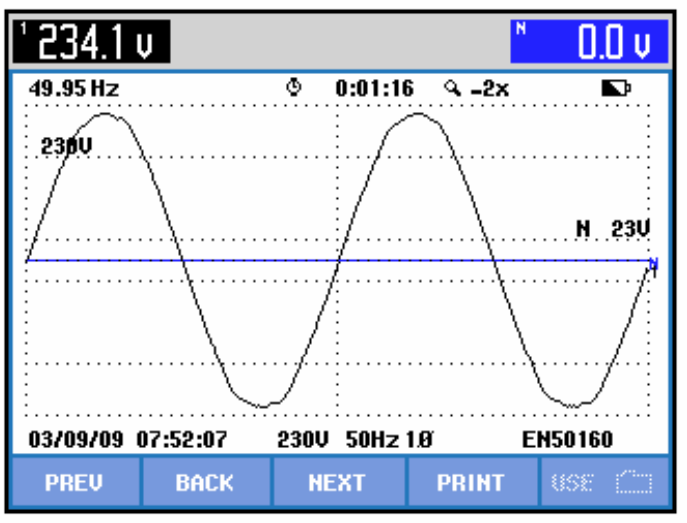

\begin{tabular}{|c|c|c|c|c|}
\hline \multicolumn{5}{|c|}{ HARMONICS TRBLE } \\
\hline Uolt & L1 & \multicolumn{2}{|c|}{ 0:00:11 } & $\frac{1}{N}$ \\
\hline $\begin{array}{l}\text { THD\%r } \\
\text { H3\%r } \\
\text { H5\%r } \\
\text { H7\%r } \\
\text { H9\%r } \\
\text { H11\%r } \\
\text { H13\%r } \\
\text { H15\%r }\end{array}$ & $\begin{array}{l}1.8 \\
0.6 \\
1.2 \\
0.8 \\
0.1 \\
0.6 \\
0.4 \\
0.1\end{array}$ & & & $\begin{array}{r}98.4 \\
2.1 \\
2.5 \\
2.4 \\
2.0 \\
2.1 \\
2.2 \\
2.4\end{array}$ \\
\hline \multicolumn{2}{|c|}{ 03/09/09 $07: 52: 27$} & $230050 \mathrm{r}$ & & EN50160 \\
\hline PREU & BACK & HEXT & PRINT & |⿰纟s: : : \\
\hline
\end{tabular}

Fig. 17. Parameters of load voltage when UVC operates.

AC/DC Converter maintains power factor $K_{P}$ higher than 0.98 both in rectifier and inverter modes, regardless of the load type. The experimental study shows effective operation of UVC with different linear and non-linear loads. Fig.11 and Fig.12 display oscillograms illustrating the operation of Bidirectional $\mathrm{AC} / \mathrm{DC}$ Converter in rectifier and inverter operational modes, respectively.

The result shows the sine waveform of the source network current, which is either in phase with or displaced at $180^{\circ}$ to the voltage of the source network.

Fig. 13 illustrates the reaction of UVC at unsteady change of the value of the source network voltage about $20 \%$ in direction of its decrease and its increase within the interval of about $3 \mathrm{~s}$. The time span on X-axis is $10 \mathrm{~s}$. Therefore, one can see the change of the maximum value of the sinewave of the voltage within the discussed interval without seeing the sine itself. The control and regulation systems of both converters of the UVC and their operational principles allow the change of the voltage towards the consumer to be significantly lower.

Fig. 14 displays results for parameters of load voltage value, harmonic spectrum, total harmonic coefficient, when the Unified Voltage Conditioner - UVC does not operate. The effective value of the voltage is with about $13 \%$ lower than

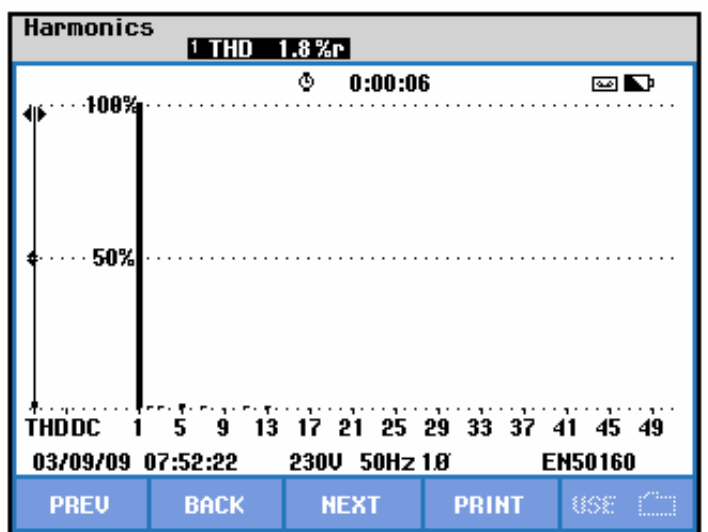

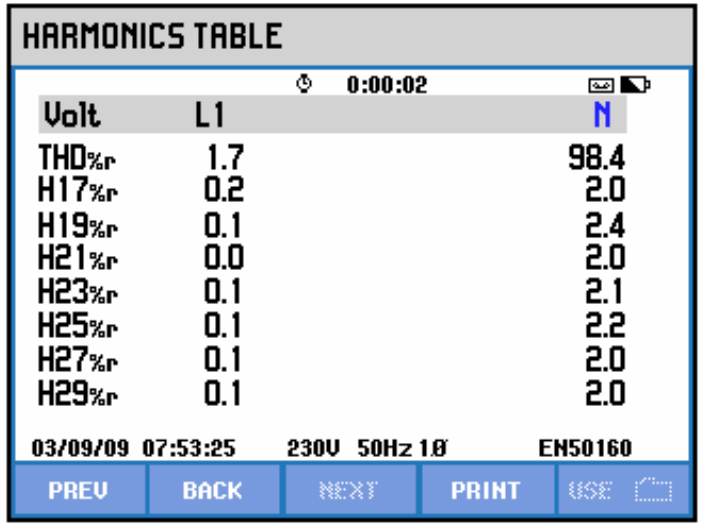

the nominal one. The harmonic coefficient is $4.5 \%$ and the fifth harmonic has the highest value. The distortion in the voltage waveform is typical for the cases when non-linear consumers, such as uncontrolled rectifiers with active-capacitive type of load, are connected to the source network.

Fig. 15 displays the data obtained when Unified Voltage Conditioner - UVC operates. It is seen that the effective value of the voltage for the consumer is stabilized to $230 \mathrm{~V}-$ $1.2 \%$, and also there is decrease in the value of all harmonics leading to the total harmonic coefficient of $1.6 \%$.

Fig. 16 displays parameters of load voltage - value, harmonic spectrum, total harmonic coefficient, when UVC does not operate. The effective value of the voltage is about $10 \%$ higher than the nominal one, the harmonic coefficient is $3.2 \%$ and the fifth harmonic has the highest value. The distortion in the voltage waveform is typical for the cases when non-linear consumers, such as uncontrolled rectifiers with active-capacitive type of load, are connected to the source network.

Fig. 17 displays the data obtained when Unified Voltage Conditioner - UVC operates. It is seen that the effective value of the voltage for the consumer is stabilized to $230 \mathrm{~V}+$ $1.2 \%$, and also there is decrease in the value of all harmonics 
leading to the total harmonic coefficient of $1.8 \%$.

\section{CONCLUSIONS}

In the paper Unified Voltage Conditioner - UVC is discussed. This schema removes non sinusoidal parts of the source network voltage waveform and the value of the sinusoidal voltage for the load is stabilized. Structural schematics are included and algorithms of operation of the control systems of bidirectional AC/DC converter and Series Active Power Filter - SAPF, included in UVC, are illustrated. To determine the total power of a series active power filter and the change of the effective value of the load voltage, analytic equations are derived and also graphical relationships are included. The results put in the paper may be used in design of three-phase version of UVC.

\section{ACKNOWLEDGMENT}

The results presented in the paper are connected with the project of researches VU-TN-116 between The Ministry of Education and Science of Bulgaria and Technical University Sofia.

\section{REFERENCES}

[1] L. G. Hingorani and L. Gyugyi, Understanding FACTS: concepts and technology of flexible AC transmission systems, USA/New York: IEEE Press, 2000.

[2] L. M. Tolbert, T. J. King, B. Ozpineci, J. B. Campbell, G. Muralidharan, D. T. Rizy, A. S. Sabau, H. Zhang, W. Zhang, Y. Xu, H. Huq, and L. Fand, "Power Electronics for Distributed Energy Systems and Transmission and Distribution Applications," USA: OAK Ridge National Laboratory, Retrieved from http://www.ornl.gov, 2005.

[3] T. Funaki, "High power electronics in Japan-backgrounds and applications," IEEE Power Electronics Society Newsletter, Vol. 18, No. 4, pp.13-15, 2006.

[4] F. Blaaberg, Z. Chen, and S. Kjaer, "Power electronics as efficient interface in dispersed power generation systems," IEEE Trans. Power Electron., Vol. 19, No. 5, pp.1184-1194, Sep. 2004.

[5] R. Teodoresku, and F. Blaaberg, "Photovoltaic systems are with power electronics," IEEE Power Electronics Society Newsletter, Vol. 17, No. 4, pp.10-13, 2005.

[6] M. Molinas, J. A. Suul, and T. Undeland, "Low voltage Ride Thrrough of wind Farms with cagr generators: STATCOM versus SVC," IEEE Trans. On Power Electronics, Vol. 23, No. 3, pp.1104-1117, May 2008.

[7] C. Meyer, R.W. de Doncker, Y.W. Li, and F. Blaabjerg, "Optimized control strategy for a medium-voltage DVR theoretical investigations and experimental results," IEEE Trans. Power Electron., Vol.23, No. 6, pp. 2746-2754, Nov. 2008.

[8] H. Akagi, "Modern active filters and traditional passive filters," Bulletin of the Polish academy of sciences, Vol. 54, No. 3, pp. 255-269, 2006.

[9] B. Sigh, K. Al-Haddad, and A.Chandra, "A review of active filters for power quality improvement," IEEE Trans. Ind. Electron., Vol. 46, No. 5, pp.960-971, Oct. 1999.

[10] Y. K. Lo, T. P. Lee, and K. H. Wo, "Grid-connected photovoltaic system with power factor correction," IEEE Trans. Ind. Electron., Vol. 55, No. 5, pp.2224-2227, May 2008.

[11] GE Energy, Voltage Conditioner Plate, GEH-6552, Rev.4, 2011.

[12] M. George, and Basu K. P., Universal Power Quality Conditioner, WSEAS Transactions on Power Systens, Vol.4, No 3, pp.95-104, 2009.

[13] A. Teke, and M. Tumay, "Unified power quality conditioner: a literature survey," Journal of Electrical Systems, Vol. 7, No. 1, pp.122-130, 2011.

[14] Y. Hoseynpoor, T. PirzadehAshraf, Sh. Sajedi, and T. Karimi, "A new mthod for simulattion and modeling of universal power quality conditioning system," Australian Journal of Basic and Applied Sciences, Vol. 5, No. 10, pp. 1239-1247, 2011.

[15] T. C. Green, J. H. Marcs, "Control Techniques for Active Power FIlters," IEE Proceedings Electric Power Applications, Vol. 152, No. 2, pp. 369-381, 2005.

[16] T. Narongrid, K. L. Areera, and K. N. Areerak, "The comparision study of current control techniques for active power filters," Word Academy of Science, Engineering and Technology, Vol. 60, pp.471-476, 2011.

[17] R. Rao, and S. S. Dash, "Enhancement of power quality by using unified power quality conditioner with pid and fuzzy logic controller," International Journal of Computer Applications, Vol. 5, No. 7, pp.21-27, 2010.

[18] M. Antchev, M. Petkova, and A. Kostov, "Hysteresis current control of single phase shunt active power filter using frequency limitation," $5^{\text {th }}$ IASTED International Conference PES, pp. 234-238, 2007.

[19] M. Antchev, M. Petkova, and M. Petkov, "Single-phase shunt active power filter using frequency limitation and hysteresis current control," PCC Nagoya Conf, pp. 97-102, 2007.

[20] M. Antchev, M. Petkova, and V. Gourgoulitsov, "Sliding mode control of a series active power filter," IEEE Conf. EUROCON 2007, pp. 1344-1349, 2007.

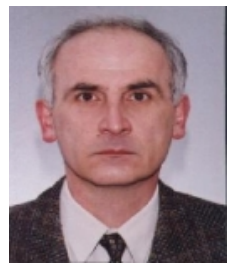

Mihail Antchev - Associate Professor, DSc - was born in Sofia, Bulgaria, in 1955. He awarded Master degree at Technical University - Sofia, Bulgaria, in 1981. He is Associate Professor in "Power electronics" from 1993. He has published about 70 scientific papers, 12 books and other school appliances. Member of IEEE - Power Electronics and Industrial Electronics Sections. He works in the field of power electronic converters with improved energy indicators, as well as of dynamic and control system of power electronic converters. 


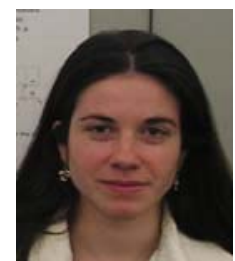

Mariya Petkova - Chief assistant, $\mathrm{PhD}$ was born in Sofia, Bulgaria, in 1979. She awarded Master degree at Technical University -Sofia, Bulgaria, in 2001. She defended $\mathrm{PhD}$ thesis titled "Methods and schemas to implement parallel active power filters" in 2007. Member of IEEE - Power Electronics Sections. She works in the field of power electronic converters with improved energy indicators and mainly in design of their control systems using microprocessors and DSPs and their software secure.

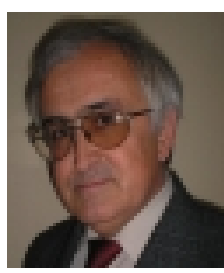

Vanjo Gourgoulitsov - Chief assistant - was born in Vidin, Bulgaria, in 1951. He graduated in Polytechnic Institute of Donetsk, Ukraine. He works in the field of power electronics, digital and microprocessor technologies, microelectronics. He receives $\mathrm{PhD}$ degree in the field of series power active filters from Technical University - Sofia 2009.

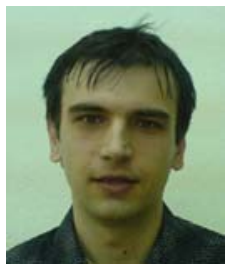

Hristo Antchev was born in Sofia, Bulgaria, in 1981. He awarded Bachelor and Master degrees at Technical University - Sofia, Bulgaria, in specialization "Power Electronics". From 2005 he works as an engineer in the field of design of power electronic converters. He also prepares $\mathrm{PhD}$ thesis "Investigation of systems of power electronic converters with common DC voltage output." 